\title{
Extended-Spectrum Beta-Lactamase Producing Strains of Escherichia Coli Isolated from Avian Cellulitis Lesions
}

\section{-Author(s)}

Kanabata B' (iD) https://orcid.org/0000-0001-6814-7322 Menck-Costa MF' (D) https://orcid.org/0000-0002-6788-7182 Souza $M^{\prime}$ (D) https://orcid.org/0000-0002-9909-6115 Justino L' (iD) https://orcid.org/0000-0002-6552-0635 Rangel IG" (D) https://orcid.org/0000-0003-3555-8277 Kobayashi RKT" (D) https://orcid.org/0000-0001-7170-2155 Nakazato G" (iD https://orcid.org/0000-0001-8624-795X Baptista AAS' (iD) https://orcid.org/0000-0003-0699-7246

Department of Preventive Veterinary Medicine, Laboratory of Avian Medicine, State University of Londrina, Paraná, Brazil.

" Department of Microbiology, State University of Londrina, Paraná, Brazil.

\section{-Mail Address}

Corresponding author e-mail address Ana Angelita Sampaio Baptista

Universidade Estadual de Londrina - UEL Rodovia Celso Garcia Cid - Pr 445, Km 388.

Campus Universitário. Cx. Postal 10011,

CEP 86057-970, Londrina - PR, Brasil.

Phone: +55 (43) 33714766

Email: anaangelita@uel.br

\section{- Keywords}

APEC; Avian cellulitis; ESBL; MDR; Virulence factor.

\section{ABSTRACT}

Avian cellulitis causes significant losses to the poultry industry. Avian-pathogenic Escherichia coli (APEC) is the etiological agent of that disease. This microorganism has zoonotic potential and may act as reservoir of antimicrobial-resistance genes. In this context, the production of extended-spectrum B-lactamase (ESBL) is one of the main antimicrobial resistance mechanisms. The objective of this study was to determine the production of ESBL in an Escherichia coli ( $E$. coli) strain isolated from avian cellulitis lesions. Twenty-two E. Coli isolates were harvested from cellulitis lesions in chicken carcasses in a commercial processing plant. Isolates were then submitted to virulence genotypic profile (iutA, hlyF, iss, ironN, ompT) analysis, antimicrobial susceptibility test, and detection of ESBL production. The results showed that $22.7 \%$ of the isolates presented five virulence genes, $9.1 \%$ four genes, $36.4 \%$ three genes, $13.6 \%$ two genes, and $18.2 \%$ one gene. The tested isolates showed resistance to ampicillin (90.9\%), ceftiofur (54.5\%), gentamicin (45.5\%), tetracycline (72.1\%), sulfamethoxazole/ trimethoprim (54.5\%), and enrofloxacin (54.5\%). Furthermore, $77.3 \%$ of the isolates presented multidrug resistance (MDR) profile and $72.7 \%$ were positive for ESBL production. This study is the first description of ESBL-producing APEC isolated from avian cellulitis lesions, which suggests the need to establish efficient APEC control measures and programs to prevent flock productivity losses due to colibacillosis and public health risks.

\section{INTRODUCTION}

Avian cellulitis is an emerging disease that has caused significant economic losses to the poultry industry (Quel et al.,2013). It is a multifactorial disease resulting from management failures, immunosuppressive diseases, and skin lesions. The lesions, often referred to as "plaques," are typically located in the skin on the abdomen or between the thigh and the midline, and therefore, are identified only after slaughter (Barnes et al., 2008).

Escherichia coli (E. coli) is considered a heterogeneous group of pathogens with wide diversity of virulence factors (Cunha et al., 2014) and may cause different clinical manifestations, such as airsacculitis, perihepatitis, pericarditis, sepsis, salpingitis, coligranuloma, and cellulitis (Barnes et al., 2008).

Avian pathogenic Escherichia coli (APEC) belongs to the pathotype extraintestinal pathogenic Escherichia coli (ExPEC) (Lestrange et al., 2017). Studies indicate that APEC has zoonotic potential, considering its profile of virulence genes and its capacity of acting as a reservoir of antimicrobial resistance genes, which can be transmitted to humans through the food chain (Aslam et al., 2014; Cunha et al., 2014). 
Kanabata B, Menck-Costa MF, Souza M, Justino L, Rangel IG, Kobayashi RKT, Nakazato G, Baptista AAS
Extended-Spectrum Beta-Lactamase Producing Strains of Escherichia Coli Isolated from Avian Cellulitis Lesions
One the hypothesis for the selection of resistant microorganisms is the extensive use of antimicrobials in animal production (Cunha et al., 2014, Hoelzer et al., 2017). The phenomenon of antimicrobial resistance poses a serious problem to human as well as veterinary medicine. The production of extendedspectrum beta-lactamase (ESBL) is one of the main resistance mechanisms of bacteria to antibiotics. This enzyme hydrolyzes the $\beta$-lactam ring of several antibiotics, including cephalosporin of third and fourth generations, penicillin, cephalosporin (ceftazidime, cefotaxime, ceftriaxone) and monobactam (aztreonam), inactivating them and, consequently, reducing treatment options (Casella et al., 2017; Shaikh et al., 2015).

Determining the virulence profile is essential to differentiate APEC isolates from non-pathogenic $E$. coli residing in the natural microbiota. In addition, the detection of virulence factors and antimicrobial resistance helps understanding the epidemiology and allows designing measures for the prevention and control of the disease. This study aimed at establishing the profile of virulence genes, phenotypic resistance to antimicrobials, and ESBL-producing capacity of APEC isolates obtained from avian cellulitis lesions.

\section{MATERIALSAND METHODS}

\section{Bacterial isolates}

Swabs of lesions [ $n=42$ ] compatible with cellulitis were collected from broiler carcasses in the slaughter line of a broiler processing plant in northern Paraná State, Brazil. Samples were collected at three different times at 7-d intervals in order to obtain isolates from flocks from different sources. Sterile swabs were rubbed on the lesions, refrigerated $\left(2-8^{\circ} \mathrm{C}\right)$ in Cary Blair medium and submitted, under refrigeration, to the Laboratory of Avian Medicine, State University of Londrina, for processing.

Swabs were incubated in $\mathrm{BHI}$ broth (Brain Heart Infusion, Difco ${ }^{\circledR}$, France) at $37^{\circ} \mathrm{C}$ for $18-24 \mathrm{~h}$, and streaked on MacConkey agar (Acumedia ${ }^{\circledR}$, USA) plates and incubated at $37^{\circ} \mathrm{C}$ for $18-24 \mathrm{~h}$. The isolated colonies were subjected to biochemical tests, and the colonies compatible with E. coli (positive for indole, negative for $\mathrm{H}_{2} \mathrm{~S}$, negative for citrate and urease, gas production in TSI (triple sugar iron) agar with acid slant and acid butt, sorbitol-fermenting) were stored at $-20^{\circ} \mathrm{C}$ in $\mathrm{BHI}$ broth supplemented with glycerol $(20 \%)$ until processing, totaling $22 \mathrm{E}$. coli isolates.

\section{Antimicrobial susceptibility test}

The disk diffusion test was applied to determine the antimicrobial susceptibility profile of the isolate, according to the protocol of the Clinical and Laboratory Standards Institute (CLSI, 2015). The Escherichia coli strain ATCC 25922 was used as control. The following antimicrobials were tested: ampicillin $(10 \mu \mathrm{g})$, ceftiofur $(30 \mu \mathrm{g})$, gentamicin $(10 \mu \mathrm{g})$, tetracycline $(30 \mu \mathrm{g})$, sulfamethoxazole/trimethoprim $(23.75 / 1.25 \mu \mathrm{g})+$ enrofloxacin $(5 \mu \mathrm{g})$. Isolates showing resistance to three or more classes of antimicrobials were considered multidrug-resistant (MDR) phenotypes (Magiorakos et al., 2012).

\section{Phenotypic profile of ESBL production}

The production of extended-spectrum betalactamase (ESBL) was determined by the disk approximation test (D-test), according to the Clinical and Laboratory Standards Institute (CLSI, 2015). Four antimicrobial agents were tested using the double-disk synergy test: amoxicillin +clavulanic acid (AMX/C-20/10 $\mu \mathrm{g})$, ceftazidime (CAZ-30 $\mu \mathrm{g})$, ceftriaxone (CRO-30 $\mu \mathrm{g})$, cefotaxime $(C T X-30 \mu \mathrm{g})$. The AMX/C disc was applied at the center of the plate containing Mueller Hinton $\left(\mathrm{MH}\right.$; Difco $\left.{ }^{\circledR}\right)$ agar and the others at a distance of 20 $\mathrm{mm}$ from the edge of the central disk. Isolates in plates showing any distortion or increase in the area of the amoxicillin-clavulanate disk was considered positive for ESBL production.

\section{Determination of virulence factors}

E. coli isolates were grown in $\mathrm{BHI}$ broth, and then subjected to DNA extraction. The boiling technique was applied, consisting of centrifugation of $1.5 \mathrm{~mL}$ bacterial growth for $1 \mathrm{~min}$ at $7500 \times \mathrm{g}$. The precipitate was suspended in $200 \mu \mathrm{L}$ of ultrapure sterile water, incubated at $100^{\circ} \mathrm{C}$ for $10 \mathrm{~min}$, and centrifuged again for $5 \mathrm{~min}$ at $2800 \times \mathrm{g}$. Next, $150 \mu \mathrm{L}$ of the supernatant were removed and stored at $-20^{\circ} \mathrm{C}$ until use.

The virulence genes iutA, hlyF, iss, ironN and ompT were studied in the isolates following the protocol described by Johnson et al. (2008).

\section{RESULTS}

\section{Phenotypic resistance to antimicrobials and ESBL production}

Significant resistance of the bacterial isolates was detected against ampicillin (90.9\%), tetracycline (72.1\%), ceftiofur (54.5\%), enrofloxacin (54.5\%), 
Kanabata B, Menck-Costa MF, Souza M, Justino L, Rangel IG, Kobayashi RKT, Nakazato G, Baptista AAS

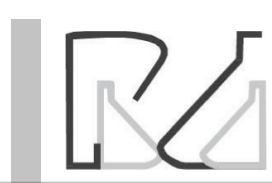

Extended-Spectrum Beta-Lactamase Producing Strains of Escherichia Coli Isolated from Avian Cellulitis Lesions

Figure 1 shows the distribution of virulence genes in the $E$. coli isolates evaluated. The most prevalent genes were iutA and $h / y F$, in $77.3 \%$ and $72.7 \%$ of the isolates, respectively, iroN was observed in $63.6 \%$, while the ompT and iss genes were detected in only $45.4 \%$ of the isolates.

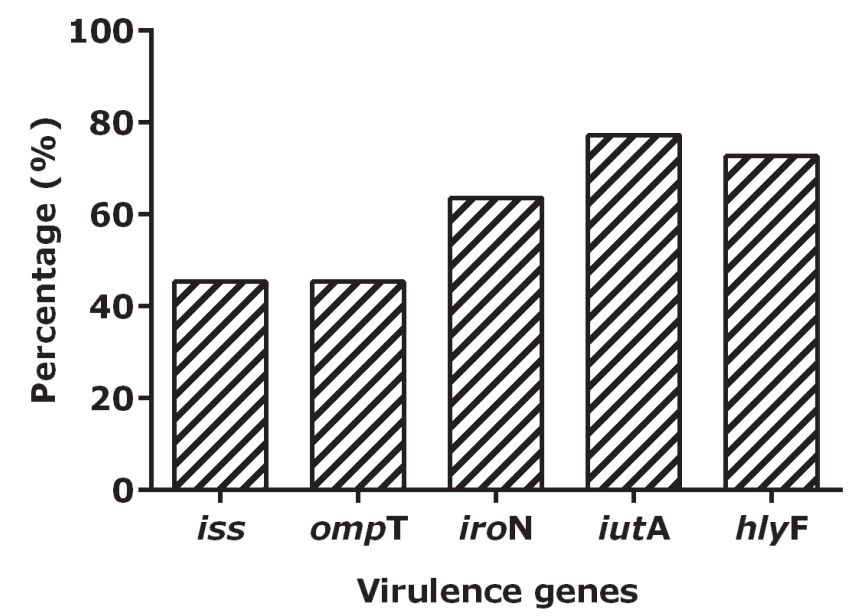

Figure 1 - Distribution of virulence genes (iss, ompT, iroN, iutA, hlyF) in samples of Escherichia coli isolated from avian cellulitis lesions.

\section{DISCUSSION}

Twenty-two E. coli isolates were obtained from cellulitis lesions in chicken carcasses, out of which $22.7 \%(5 / 22)$ presented five virulence genes (iss, ompT, iroN, iutA, hlyF), 9.1\% (2/22) four genes, 36.4\% (8/22) three genes, $13.6 \%(3 / 22)$ two genes, and $18.2 \%$ $(4 / 22)$ only one gene (Table 2$)$.

Table 2 - Relationship of virulence genes and their combinations in samples of Escherichia coli isolated from avian cellulitis lesions.

\begin{tabular}{lc}
\hline Genes & Number of samples (\%) \\
\hline iss & $0 / 22(0 \%)$ \\
ompT & $0 / 22(0 \%)$ \\
iroN & $0 / 22(0 \%)$ \\
iutA & $2 / 22(9.1 \%)$ \\
hlyF & $2 / 22(9.1 \%)$ \\
iss + ompT & $1 / 22(4.5 \%)$ \\
iroN + iutA & $1 / 22(4.5 \%)$ \\
iutA + hlyF & $1 / 22(4.5 \%)$ \\
iss + ompT + iutA & $2 / 22(9.15 \%)$ \\
iroN + iutA + hlyF & $6 / 22(27.3 \%)$ \\
iss + ompT + iroN + hlyF & $2 / 22(9.1 \%)$ \\
iss + ompT + iroN + iutA + hlyF & $5 / 22(22.7 \%)$ \\
\hline
\end{tabular}

The genes iss, ompT and iroN were not detected in any of the isolates evaluated. In the present study, $27.3 \%(6 / 22)$ of isolates showed the combination of iroN, iutA and hlyF genes. Conversely, the presence of individual genes was observed in $18.2 \%$ of the isolates, with $9.1 \%$ prevalence of iutA and hlyF.

Escherichia coli is a natural resident of the intestinal microbiota of birds and mammals; however, some pathotypes designated avian pathogenic $E$. coli (APEC) may invade different organs and cause systemic disease or colonize individual tissues, such as the case of cellulitis (Li et al., 2015).

The present study determined the virulence gene profile, phenotypic resistance to antimicrobials, and extended-spectrum beta-lactamase (ESBL) production of APEC isolates collected from avian cellulitis lesions. The objective was to demonstrate that the antimicrobial resistance profile of a microorganism may cause disease in broilers and pose a public health risk through the food chain, transferring resistance genes to potential human pathogens.

To the best of our knowledge, this is the first study to describe ESBL-producing APEC isolates in avian cellulitis lesions, although other studies have isolated ESBL-positive E. coli strains in live chickens and poultry products (Lim et al., 2015; Hussain et al., 2017; Silva et al., 2017).

Antimicrobial therapy is one of the primary control measures to reduce morbidity and mortality caused by APEC (Barbieri et al., 2013). However, the frequent use of antimicrobials allows the selection of resistant isolates, which is a global health concern (Nhung et al., 2017). 
Kanabata B, Menck-Costa MF, Souza M, Justino L, Rangel IG, Kobayashi RKT, Nakazato G, Baptista AAS
Extended-Spectrum Beta-Lactamase Producing Strains of Escherichia Coli Isolated from Avian Cellulitis Lesions
In the present study, $77.3 \%$ of the isolates evaluated presented the MDR phenotype, which presented high resistance to ampicillin $(90.9 \%)$ and tetracycline (72.1\%). Similarly, Barbieri et al. (2013) found a high percentage of resistance to tetracycline $(69.4 \%)$ in $E$. coli isolated from avian cellulitis in broilers in southern Brazil. Wu et al. (2014) found 84.4 and $71.1 \%$ of resistance to tetracycline and ampicillin, respectively, in E. coli isolates from poultry in China.

In our study, $54.5 \%$ of the isolates showed resistance to sulfamethoxazole/trimethoprim. This profile is alarming because these drugs are the first choice for the treatment of human patients in intensive care units (Brown \& Foxman, 2002). Chen et al. (2014) observed that $90.6 \%$ APEC isolate were resistant to tetracycline, and suggest a co-resistance relationship among tetracycline, trimethoprim-sulfamethoxazole, and ampicillin.

In addition to public health aspects, the presence of antimicrobial-resistant pathogenic microorganisms directly affects livestock production, since it undermines treatments and prolong the disease in animals, reducing therapeutic alternatives, increasing production costs, and reducing profitability (El-Shazly et al., 2017).

ESBL production is an important resistance mechanism to antimicrobials (Daehre et al., 2017). In our study, the ESBL phenotype was present in $72.1 \%$ of the isolates, which is significant. This result is consistent with those reported by Casella et al. (2017), who observed $96.1 \%$ (74/77) positivity for ESBL in $E$. coli isolates from poultry in France. Our study is the first description of ESBL-producing APEC isolated from avian cellulitis lesions.

According to Johnson et al. (2008), the iutA, hlyF, iss, iroN and ompT genes are associated with plasmids and are considered good APEC markers, although other markers have been described. Our findings are consistent with those of Hiki et al. (2014), who determined that iutA and hlyF as the first and second most prevalent virulence genes in Escherichia coli isolates from healthy broilers in Japan.

Ozaki et al. (2017) observed that iss gene was present in $93 \%$ of APEC isolates from perihepatite and pericarditis lesions in broilers. These data differ from our results, since iss was observed in $45 \%$ of the isolates. This difference may be attributed to the fact that we analyzed isolates from cellulitis lesions, whereas Ozaki et al. (2017) worked with isolates causing septicemia. According to Silveira et al. (2016), the presence of the ompT, iroN, and iss genes is correlated with disease severity, while the hlyF and iutA genes are involved with the capacity of causing disease. Therefore, we can infer that $27 \%$ of the isolates in the present study had capacity of causing severe disease.

\section{CONCLUSIONS}

The identification of APEC isolates from avian cellulitis lesions containing virulence genes with capacity of producing ESBL and MDR suggests the need to establish efficient APEC control measures and programs in order to reduce flock productivity losses due to colibacillosis and public health risks.

\section{REFERENCES}

Aslam M, Toufeer M, Narvaez Bravo C, Lai V, Rempel H, Manges A, et al. Characterization of extraintestinal pathogenic escherichia coli isolated from retail poultry meats from Alberta, Canada. International Journal of Food Microbiology 2014;177:49-56.

Barbieri NL,Oliveira AL,Tejkowski TM, Pavanelo DB, Rocha DA, Matter LB, et al. Genotypes and pathogenicity of cellulitis isolates reveal traits that modulate APEC virulence. PLOS ONE 2013;8(8):e72322.

Barnes HJ, Vaillancourt J, Gross WB. Colibacillosis. In: Saif YM, Fadly AM, Glisson JR, McDougald LR, Nolan LK, Swayne DE, editors. Diseases of poultry. $12^{\text {th }}$ ed. Ames: Blackwell Publishing; 2008.

Brown PD, Freeman A, Foxman B. Prevalence and predictors of trimethoprimsulfamethoxazole resistance among uropathogenic Escherichia coli isolates in Michigan. Clinical Infectious Diseases 2002;34(8):10611066.

Casella T, Nogueira MCL, Saras E, Haenni M, Madec JY. High prevalence of ESBLs in retail chicken meat despite reduced use of antimicrobials in chicken production, France. International Journal Food Microbioly 2017;257(18):271-275.

Chen X, Zhang W, Yin J, Zhan N, Geng S, Zhou X, et al. Escherichia coli isolates from sick chickens in China: Changes in antimicrobial resistance between 1993 and 2013. Veterinary Journal 2014;202(1):112-115.

CLSI - Clinical and Laboratory Standards Institute. Performance standards for antimicrobial susceptibility testing. $25^{\text {th }}$ ed. Wayne; 2015.

Cunha MPV, Oliveira MGX, Oliveira MCV, Silva KC, Gomes CR, Moreno AM, et al. Virulence profiles, phylogenetic background, and antibiotic resistance of escherichia coli isolated from turkeys with airsacculitis. Scientific World Journal 2014; 2014 (2):8.

Daehre K, Projahn M, Semmler T, Roesler U, Friese A. Extended-spectrum beta-lactamase-/ampc beta-lactamase-producing enterobacteriaceae in broiler farms: transmission dynamics at farm level. Microbiology Drug Resistance 2017;24(4):511-518.

El-Shazly DA, Nasef SA, Mahmoud FF, Jonas D. Expanded spectrum $\beta$ lactamase producing Escherichia coli isolated from chickens with colibacillosis in Egypt. Poultry Science 2017;96(7):2375-2384.

Hiki M, Usui M, Akiyama T, Kawanishi M, Tsuyuki M, Imamura S, et al. Phylogenetic grouping, epidemiological typing, analysis of virulence genes, and antimicrobial susceptibility of Escherichia coli isolated from healthy broilers in Japan. Irish Veterinary Journal 2014;67(1):14.

Hoelzer K, Wong N, Thomas J, Talkington K, Jungman E, Coukell A Antimicrobial drug use in food-producing animals and associated human health risks: what, and how strong, is the evidence? BMC Veterinary Research 2017; 13(1):211. 
Kanabata B, Menck-Costa MF, Souza M, Justino L, Rangel IG, Kobayashi RKT, Nakazato G, Baptista AAS
Hussain A, Shaik S, Ranjan A, Nandanwar N, Tiwari SK, Majid M, et al. Risk of transmission of antimicrobial resistant escherichia coli from commercial broiler and free-range retail chicken in India. Frontier in Microbiology 2017; 8:2120.

Johnson TJ, Wannemuehler Y, Doetkott C, Johnson SJ, Rosenberger SC, Nolan LK. Identification of minimal predictors of avian pathogenic Escherichia coli virulence for use as a rapid diagnostic tool. Journal Clinical Microbiology 2008;46(12):3987-3996.

Lestrange K, Markland SM, Hoover DG, Sharma M, Kniel KE. An evaluation of the virulence and adherence properties of avian pathogenic Escherichia coli. One Health 2017;4:22-26.

Li Y, Chen L, Wu X, Huo S. Molecular characterization of multidrug-resistant avian pathogenic Escherichia coli isolated from septicemic broilers. Poultry Science 2015;94(4):601-611.

Lim JS, Choi DS, Kim YJ, Chon JW, Kim HS, Park HJ, et al. Characterization of Escherichia coli-producing extended-spectrum $\beta$-lactamase (esbl) isolated from chicken slaughterhouses in South Korea. Foodborne Pathogens and Disease 2015;12(9):741-748.

Magiorako AP, Srinivasan A, Carey RB, Carmeli Y, Falagas ME, Giske CG, et al. Multidrug-resistant, extensively drug-resistant and pandrugresistant bacteria: an international expert proposal for interim standard definitions for acquired resistance. Clinical Microbiology and Infection 2012;18:268-281.

Nhung NT, Chansiripornchai N, Carrique-Mas JJ. Antimicrobial resistance in bacterial poultry pathogens: a review. Frontiers in Veterinary Science $2017 ; 4: 126$
Extended-Spectrum Beta-Lactamase Producing Strains of Escherichia Coli Isolated from Avian Cellulitis Lesions

Ozaki H, Matsuoka Y, Nakagawa E, Murase T. Characteristics of Escherichia coli isolated from broiler chickens with colibacillosis in commercial farms from a common hatchery. Poultry Science 2017:96(10):37173724.

Quel NG, Aragão AZ, Salvadori MR, Farias AS, Joazeiro PP, Santos LM, et al. Cellulitis lesions in broiler chickens are induced by Escherichia coli Vacuolating Factor (ECVF). Veterinary Microbiolgy 2013;162(2-4):866872.

Shaikh S, Fatima J, Shakil S, Rizvi SM, Kamal MA. Antibiotic resistance and extended spectrum beta-lactamases: Types, epidemiology and treatment. Saudi Journal of Biological Sciences 2015;22(1):90-101.

Silva KC, Cunha MP, Cerdeira L, de Oliveira MG, de Oliveira MC, Gomes CR, et al. High-virulence CMY-2-and CTX-M-2-producing avian pathogenic Escherichia coli strains isolated from commercial turkeys. Diagnostic Microbiology and Infectious Disease 2017; 87(1):64-67.

Silveira F, Maluta RP, Tiba MR, de Paiva JB, Guastalli EA, da Silveira WD. Comparison between avian pathogenic (APEC) and avian faecal (AFEC) Escherichia coli isolated from different regions in Brazil. Veterinary Journal 2016;217:65-67.

Wu Q, Xi M, Lv X, Xu Y, Feng Y, Li Q, et al. Presence and antimicrobial susceptibility of Escherichia coli recovered from retail chicken in China. Journal of Food Protection 2014:77(10):1773-1777. 
